\title{
Evaluating expert knowledge: Plant species responses to cattle grazing and fire
}

\author{
RICARDO M. RODRÍGUEZ IGLESIAS AND MORT M. KOTHMANN
}

Authors are post-dactoral research associate and professor, Department of Rangeland Ecology \& Management, Texas A\&M University, College Station, Tex. 77843-2126,

\author{
Abstract
}

Expert judgment, standardized in a meaningful format, can be used to identify research/survey needs and to characterize areas of (dis)agreement in species responses, associated traits, and factors affecting responses. Feasible methods are needed to facilitate the evaluation of expertise in a complex domain characterized by moderate to low learnability.

Specific objectives for this study were 1) to evaluate agreement among experts on range plant species behavior and 2) to develop an agreement-based classification method for plant species responses. Declarative information at landscape scale was elicited from 7 role-suggested experts on expected responses to cattle grazing (none, moderate, or heavy) and fire (absent, applied in late summer or fall, or applied in late winter or spring) of 198 plant species from the Edwards Plateau (Texas). Trends were requested to be assessed in a 3-level ordinal scale (decrease, unaffected, increase). Kappa statistics (pair-wise and multi-rater versions) and log-linear models were used to evaluate agreement. $A$ procedure based upon cumulative probability distributions of possible rating combinations was developed to classify plant species while accounting for agreement. A total of 4,584 opinions (cattle graxing: 2,959; fure: 1,625 ) was elicited and analyzed. Low to moderate agreement was observed. Average pair-wise kappa statistics ranged from 0.07 to 0.39 ; multiple-rater kappa coefficients ranged from -0.17 to 0.53 . $\mathrm{Log}$-linear analyses were consistent with those estimations: agreement beyond chance or baseline association between ratings $(\mathrm{P}<0.05)$ was observed in 62 out of 114 possible pair-wise cases. Non-homogeneous marginal distributions of opinion were an important source of disagreement. Experts performed beyond chance expectations in all scenarios but agreement was better (and pattern of agreement more consistent) when scenarios were most familiar to the experts (e.g., heavy grazing and winter/spring burning). Almost $80 \%$ of species was classified beyond chance $(P<0.15)$ in grazing scenarios in contrast to only 40 to $60 \%$ in fire scenarios. This resulted from less agreement among experts but also from apparent lack of knowl edge. The procedure developed to classify plant species provides an objective criterion for evaluating agreement in an ordinal scale. Graphical representations facilitate understanding of relationships between the number of expert sources and their ability to distinguish among classes for a pre-defined confidence level.

Key Words: Distinguishability, kappa statistics, landscape scale, log-linear models, vegetation trends.

The senior author acknowledges support received from Texas Agricultural Experiment Station, Consejo Nacional de Investigaciones Científicas y Técnicas (Argentina), Centro de Recursos Naturales Renovables de la Zona Semiárida (Argentina), and Fundación Antorchas (Argentina). Seven knowledgeable individuals provided expert information for this work. Their contribution is greatly appreciated.

Manuscript accepted 13 Jul. 1997.

\section{Resumen}

Es posible aplicar conocimiento experto normalizado para identificar prioridades en investigación/relevamientos, caracterizar (des)acuerdo sobre respuestas de especies individuales, factores que las afectan y caracteres asociados. Se requieren métodos que faciliten la evaluación de conocimiento experto en un campo complejo caracterizado por una limitada capacidad de aprendizaje.

Objetivos especifícos del estudio fueron: 1) evaluar acuerdo entre expertos sobre el comportamiento de especies vegetales de campo natural y 2) desarrollar un método de clasificación basado en acuerdo. Para 198 especies vegetales del Edwards Plateau (Texas) se colectó opinión de expertos $(n=7)$ emitida a nivel de paisaje sobre tendencias esperadas bajo pastoreo con bovinos (no pastoreado, pastoreo moderado, pastoreo intenso) y fuego (no quemado, quema estivo-otonal, quema inverno-primaveral) evaluadas en una escala ordinal de 3 niveles (disminuye, no cambia, aumenta). EI acuerdo se evaluó utilizando modelos log-lineales y coeficientes kappa (versiones para 2 o varias fuentes). Se describe un procedimiento basado en distribuciones de probabilidad acumulada para clasificar especies individuales en base a acuerdo observado.

Se colectaron 4,584 opiniones (pastoreo con bovinos: 2,959; fuego: 1,625 ) cuyo análisis reveló reducido a moderado acuerdo. Los coeficientes kappa estimados variaron de 0,07 a 0,39 (promedios para pares de expertos) y de $\mathbf{- 0 , 1 7}$ a 0,53 (valores individuales para el conjunto de expertos), resultados consistentes con el análisis log-lineal que indicó acuerdo no explicado por azar o por asociación sistemática de opiniones $(P<0,05)$ en 62 de los 114 casos posibles de pares de expertos. Una parte importante del desacuerdo provino de heterogeneidad en las distribuciones marginales de opinión. Los expertos se desempeñaron más allá de lo esperado por azar en todas las situaciones estudiadas aunque se observó mayor y más consistente acuerdo en situaciones familiares para los sujetos (e.g. pastoreo intenso y quema inverno-primaveral). Casi un $80 \%$ de especies fue clasificada en base a acuerdo no explicado por azar $(P<0,15)$ en situaciones de pastoreo pero sólo entre 40 y $60 \%$ en situaciones que involucraban quemas. Ello se debió a menor acuerdo pero también a una aparente falta de conocimiento. FI procedimiento desarrollado provee un criterio de clasificación objetivo para evaluar acuerdo en escala ordinal; las representaciones gráficas implementadas facilitan el análisis de relaciones entre el número y la babilidad discriminativa de las fuentes de información para niveles de probabilidad prefíjados.

Two popular approaches for depicting vegetation change in rangelands are the succession-retrogression (Sampson 1917, 
1919. Clements 1920, Dyksterhuis 1949,1958 ) and the state-andtransition (Westoby et al. 1989a, 1989b) models. Both approaches can be characterized as equilibrium-oriented, focusing either on one (succession-retrogression) or more (state-and-transition) stable states for some temporal scale of interest (Rodríguez Iglesias and Kothmann 1997). As new theoretical and analytical tools become available to support non-balance approaches (Wiens 1984, Chesson and Case 1986, DeAngelis and Waterhouse 1987), equilibrium-seeking models have been increasingly challenged. A shift toward individualistic views on species behavior (Gleason 1926, Goodall 1963) is also evident (e.g., Johnson and Mayeux 1992, McIntosh 1995) and gaining credibility and applicability.

Individualistic approaches are seriously challenged by the amount of information and inherent difficulty associated with aggregating individual species behaviors, a required step for vegetation trend prediction. Two possible solutions to this dilemma are either limiting modeling to the representation of the most important individual plant species, or simplifying the vegetation domain by clustering species into response or functional groups (Botkin 1974). These alternatives, however, still require information not always available from experimental results or systematic field surveys.

Comparative data on individual species responses to management or environmental challenges, relevant for grouping purposes, may not be readily available. This type of information is critical for producing supervised (e.g., Rodríguez Iglesias 1996, using classification trees) rather than unsupervised (e.g., Grime et al. 1988 , using cluster analysis) classifications of plant species. Although still an untested hypothesis, prediction-oriented supervised classifications may be expected to outperform clustering approaches in anticipating vegetation changes. Constraining the characterization of groups of plant species on the basis of their expected responses to management or environmental challenges would eventually produce disturbance-related ecological profiles with better predictive capabilities (Rodríguez Iglesias 1996).

In contrast to the lack of experimental comparative information on plant species responses, knowledge gathered in management settings goes currently unused. Most of this "expert information" is qualitative rather than quantitative but it might be promptly elicited at a relatively low cost and has potential for supporting supervised classifications of plant species. Other examples of possible straightforward use of expert opinion are the assessment of herbivore preferences at landscape scale (Phillips et al. 1996, Rodríguez Iglesias and Kothmann 1998) and the parameterization of graphical belief models (Rodríguez Iglesias et al. 1998). Uncertainty in many management-related issues (e.g., vegetation change) could be greatly reduced by incorporating expert opinion as prior information that would be eventually updated as the knowledge base changes or experimental/ survey data become available. This approach roughly corresponds to the well-established Bayesian learning paradigm.

An important unsolved challenge on the use of expert opinion involves the combination or blending of different expert sources. A profusion of methods have been proposed (e.g., Genest and Zidek 1986, Kadane 1993, Dawid et al. 1995, Wiper and French 1995) but widely accepted general procedures are still lacking. Most of the proposed methods lack generality and focus on specific types of variables (e.g., continuous), distribution moments (e.g., mean values), or knowledge representation (e.g., through linear models).
In dealing with expert information on plant species responses, we confronted the problem of pooling opinions elicited in a 3 level ordinal scale and with a high incidence of missing values. A probabilistic method for handling such kind of information was developed and is described in this paper. The objective for our study was to collect and analyze expert opinion on the expected responses of a set of plant species from the Edwards Plateau (Texas) to different cattle grazing and fire scenarios. The ultimate goal of this effort, described in detail elsewhere (Rodríguez Iglesias 1996), was to combine expert opinion on plant species responses with a database of ecological attributes to produce a supervised classification of plant species.

Agreement among different sources is a key issue affecting the perceived reliability of any expert opinion-based procedure. A combination of opinions, on the other hand, is required to arrive at an expected outcome for individual cases (i.e., plant species). Thus, analyzing agreement among expert sources and developing a method for classifying plant species according to agreement were specific objectives of this work.

\section{Materials and Methods}

\section{Collection of Expert Opinion}

Nine individuals were selected to produce expert opinion concerning 2 of the most widely reported factors involved in range dynamics: grazing and fire (Rodríguez Iglesias and Kothmann 1997). It is difficult to determine when an individual qualifies as an "expert" in a domain characterized by the uncertain and complicated behavior of many interacting species populations. The informed opinion of the authors was that the 9 individuals selected would be considered experts by any qualified audience on the basis of their roles and previous experience on managing vegetation. These experts were 3 university professors, 2 researchers, and 2 extension specialists from the Texas A\&M University System, 1 range specialist from the USDA Natural Resources Conservation Service, and 1 biologist from the Texas Parks and Wildlife Department. One university professor and 1 extension specialist did not answer by due time so all results reported in the paper are based on the information provided by the remaining 7 individuals.

A list of 198 plant species from the Edwards Plateau (Texas) was sent to each expert accompanied by a short explanation of the type of information solicited. Opinion was requested on the expected trends in abundance caused by cattle grazing or fire and rated as decrease (D), unaffected (U), or increase (I). The effect of cattle grazing was to be evaluated at 3 levels of intensity: none, moderate, and heavy. The effect of fire was to be considered in 3 different scenarios: absent, applied in late summer or fall, or applied in late winter or spring. Experts worked independently. No attempts were made to standardize the process of classifying species or to constrain the distribution of species to classes. Explanatory information was provided only to clarify the kind of data requested.

We requested that the experts evaluate the effects of both disturbance factors at the landscape level, as opposed to the individual plant species level; e.g., in the case of firc, plant specics rarely exposed to fires because they grow in areas not commonly affected by prescribed burning or wildfires (e.g., riparian areas, 
steep slopes with scarce fine fuel) should be considered $U$ species even though they could be negatively affected if exposed to fire.

\section{Evaluation of Agreement Between Raters}

The problem of evaluating agreement can be described as one in which $\mathrm{N}$ cases (plant species in our case) are allocated to 1 of $\mathrm{m}$ classes by cach of $\mathbf{n}$ raters with the possibility that $\mathrm{n}$ may differ for different cases. For $n \geq 2$, the analysis may focus on pairwise agreement, g-wise agreement (where $2<\mathrm{g}<\mathrm{n}$ ), or multiway agreement in which all judgments produced by the raters are considered simultaneously; see Conger (1980) and Agresti (1992) for comprehensive reviews. Two complementary approaches for evaluating agreement are the calculation of summary measures of agreement (e.g., correlation-like statistics) and a diverse array of modeling tools that include log-linear, Rasch, and latent class models (e.g., Agresti and Lang 1993, Uebersax and Grove 1993).

The kappa coefficient ( $\mathrm{K}$; Cohen 1960) is a popular correlationlike statistic and was used to assess pair-wise agreement among raters for every grazing or fire scenario considered. Estimates of $\mathrm{K}$ were obtained as:

$$
\hat{\mathrm{K}}=\frac{\mathrm{p}_{\mathrm{o}}-\mathrm{p}_{\mathrm{c}}}{1-\mathrm{p}_{\mathrm{c}}}
$$

where $p_{0}$ is the proportion of cases in which the raters agree and $\mathrm{p}_{\mathrm{c}}$ is the proportion of cases for which agreement is expected only by chance on the assumption that the marginal distributions of ratings (see below) are independent. If $\mathrm{N}$ cases (in our case, plant species) are distributed to the $\mathrm{m}^{2}$ cells of a cross-tabulation of the opinions of 2 raters by assigning every case to 1 of $\mathrm{m}$ classes, then from the cell counts $\left(a_{i j}\right)$ :

$$
p_{i j}=\frac{a_{i j}}{N} \quad \text { po }=\sum_{i=j} \text { pij; } \quad \text { pc }=\sum_{i=j} \text { pi. p.j; }
$$

where $\mathrm{i}$ and $\mathrm{j}$ are indices corresponding to the $\mathrm{m}$ classes for each of the 2 raters (i.e., $a_{12}$ indicates cases classified in class 1 by one of the raters and in class 2 by the other while $a_{21}$ indicates the reverse situation) and the dots indicate summation over the omitted subscript. Thus, $\mathrm{K}$ is intended to assess how much agreement is observed beyond that expected just by chance. A kappa estimate of zero indicates no agreement beyond what would be expected by chance. Better than chance agreement produces positive values with an upper limit of 1 . The lower limit of the coeffi- cient is more complicated as it depends on the marginal distributions (see Cohen 1960). Arguably, however, since $\mathrm{K}$ is used to evaluate agreement, a fixed upper limit is what really matters (Cohen 1960). Table 1 shows sample calculations performed on one of the data sets included in the analyses. Frequency data are accumulated across columns and rows to obtain marginal distributions for each of the raters. Agreement expected by chance given the observed marginal distributions (i.e., $p_{c}$ ) is then calculated from marginal proportions. The term $p_{0}$ is simply the summation of cases (expressed as proportions) that received identical classification by both raters.

Standard errors and confidence intervals for the hypothesis of no agreement between raters were derived according to largesample variance formulas proposed by Fleiss et al. (1969). Confidence intervals calculated according to large sample theory do not behave very well when kappa is far from 0 and/or when sample sizes are small. In our case, $K$ values were expected to be low to moderate and sample size was moderately high so gross departures from true values are unlikely. On the other hand, better procedures for confidence interval estimation are only available for binary outcomes (Lee and Tu 1994, J.J. Lee, personal communication). Individual contributions of the $\mathrm{m}$ classes (i.e., $D, U, I)$ to overall agreement $\left(K_{\mathfrak{i}}\right)$ were estimated as:

$$
\hat{K}=\frac{p_{i j}-\left(p_{i} \cdot p_{. i}\right)}{p_{o}-p_{c}}
$$

The estimated value of $\mathrm{K}$ depends on the marginal distributions of the $\mathrm{m}$ classes which are determined by the judgments of individual raters. Thus, degree of agreement is limited by similarity of the marginal distributions. An estimate of pair-wise marginal disagreement was obtained as:

$$
\mathrm{d}=1-\frac{\left[\sum \min \left(\mathrm{p}_{\mathrm{i}}, \mathrm{p}_{\mathrm{j}}\right)\right]-\mathrm{p}_{\mathrm{c}}}{1-\mathrm{p}_{\mathrm{c}}}
$$

where $\min \left(\mathrm{p}_{\mathrm{i}}, \mathrm{p}_{\mathrm{j}}\right)$ indicates selecting the smaller of the 2 indicated proportions.

Pair-wise agreement was also evaluated using a log-linear approach (Goodman 1979, Tanner and Young 1985, Agresti 1988). A generalized linear model (McCullagh and Nelder 1989) with Poisson error distribution and logarithmic link function can be used to partition overall agreement into 3 components: chance

Table 1. Sample Calculations of the coefficient of agreement $(K)$ and associated statistics for a representative set of frequencies distributed among 2 rates.

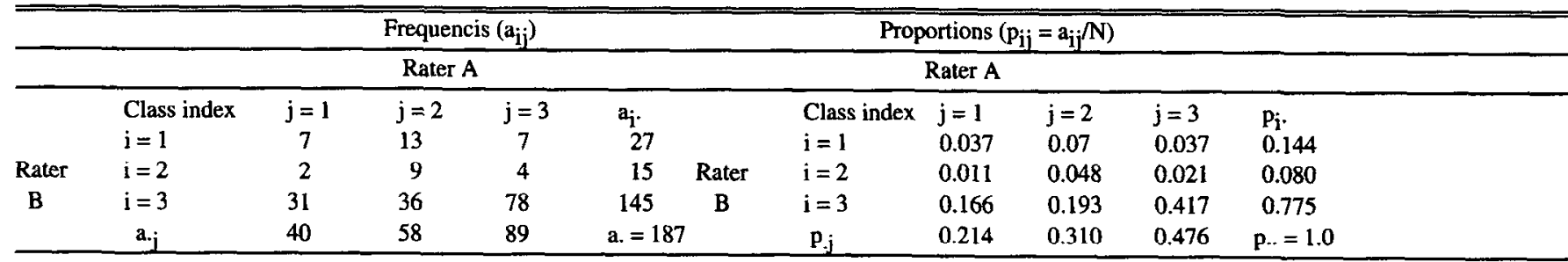

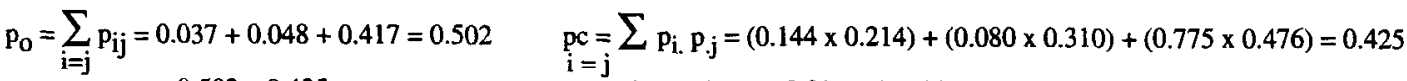

$$
\begin{aligned}
& \hat{\mathrm{K}}=\frac{\mathrm{p}_{\mathrm{c}}-\mathrm{p}_{\mathrm{c}}}{1-\mathrm{pc}}=\frac{0.502-0.425}{1-0.425}=0.135 \quad \hat{\mathrm{K}}=\frac{\mathrm{p}_{11}-\left(\mathrm{p}_{1 .} \mathrm{p}_{.1}\right)}{\mathrm{p}_{\mathrm{o}}-\mathrm{p}_{\mathrm{c}}}=\frac{0.037-(0.144 \times 0.214)}{0.502-0.425}=0.084 \\
& \hat{\mathrm{d}}=1 \frac{\left[\sum_{\mathrm{i}=\mathrm{j}} \min \left(\mathrm{p}_{\mathrm{i} .}, \mathrm{p}_{\mathrm{j}}\right)\right]-\mathrm{pc}}{1-\mathrm{p}_{\mathrm{c}}}=1-\frac{(0.144+0.08+0.476)-0.425}{1-0.425}=0.521 \\
& \text { Similarly, } \hat{\mathrm{K}}_{2}=0.299 \text { and } \hat{\mathrm{K}}_{3}=0.617
\end{aligned}
$$


agreement, agreement due to baseline association between the ratings, and extra agreement in excess of chance or baseline association. Null hypotheses concerning the third one of these components in the so-called "model of agreement plus linear-by-linear interaction" (Agresti 1988) were tested using likelihood ratio statistics. Functions for generalized linear model fitting in S-Plus version 3.2 (Statistical Sciences Inc. 1993) were used for calculations." A multiple-rater version of the K coefficient (Fleiss 1971) was used to evaluate overall agreement among raters. Ratings on individual species were classified according to the number of opinions received ( 0 to 7 ) and coefficients of multiple agreement $\left(\mathrm{K}_{\mathrm{m}}\right)$ were calculated for groups of species receiving at least 2 and up to 7 ratings according to:

$$
\begin{gathered}
\hat{\mathbf{K}} \mathrm{m}=\frac{\mathrm{p}_{\mathrm{m}}-\mathrm{p}_{\mathrm{e}}}{1-\mathrm{p}_{\mathrm{e}}} \\
\mathrm{pm}=\frac{\sum_{\mathrm{k}=1}^{\mathrm{N}} \mathrm{P}_{\mathrm{k}}}{\mathrm{N}} ; \mathrm{pe}=\sum_{\mathrm{i}=1}^{\mathrm{k}} \mathrm{p}_{1}^{2} ; \mathrm{Pk}=\frac{\sum_{\mathrm{i}=1}^{\mathrm{m}} \mathrm{a}_{\mathrm{ik}}\left(\mathrm{a}_{\mathrm{ik}}-1\right)}{\mathrm{n}(\mathrm{n}-1)} \quad \mathrm{pi}=\frac{\sum_{\mathrm{k}=1}^{\mathrm{N}} \mathrm{a}_{\mathrm{ik}}}{\mathrm{Nn}}
\end{gathered}
$$

where $i$ indicates classes as before, $k$ is the index for cases and, therefore, $a_{i k}$ stands for the number of raters who assigned the $k^{\text {th }}$ case to the $\mathrm{i}^{\text {th }}$ class. Sample calculations for plant species that received exactly 6 ratings for the Summer/ fall fire scenario are shown in Table 2 . The term $P_{k}$ evaluates, for each case, the proportion of agreeing pairs of ratings in relation to the total number of possible pairs that can be formed with $n$ raters (i.e., $n(n-1)$ ). The term $\mathrm{P}_{\mathrm{m}}$, in turn, is the average of those proportions, calculated over the entire set of cases. Agreement by chance $\left(\mathrm{p}_{\mathrm{e}}\right)$ is calculated from marginal proportions, as for the pair-wise case (see above).

For hypotheses concerning multiple agreement, variances were estimated according to the approximation developed by Fleiss (1971). Such an approximation assumes that $\mathbf{N}$ is large and therefore the proportions $p_{i}$ can be considered constant. Agreement on assignments to individual classes $\left(\mathrm{K}_{\mathrm{mi}}\right)$ was estimated as:

$$
\hat{\mathbf{K}}_{\mathrm{mi}}=\frac{\mathrm{p}_{\mathrm{mi}}-\mathrm{p}_{\mathrm{i}}}{1-\mathrm{p}_{\mathrm{i}}}
$$

where

$$
\mathrm{p}_{\mathrm{mi}}=\frac{\sum_{\mathrm{a}}^{2}-\mathrm{Nnp}}{\mathrm{Nn}(\mathrm{n}-1) \mathrm{p}_{\mathrm{i}}}
$$

and $\mathrm{p}_{\mathrm{i}}$ is defined above. Estimated variances required for hypothesis testing were computed as described by Fleiss (1971).

\section{Assignment of Species to Classes}

Calculation of $\mathrm{K}$ coefficients and ancillary log-linear analyses allowed a straightforward evaluation of agreement. However, a different approach was required for defining a useful criterion for distinguishing plant species classified in a similar way from those for which there was less or no agreement among raters. As indicated in the Introduction section, rating plant species according to agreement on expected responses would eventually allow the use of supervised classification methods. Any approach for evaluating agreement on a plant species basis should allow for different numbers of opinions received per species, which in our case varied from 0 to 7 . The following procedure was developed for that purpose.
Table 2. Sample calculations of the coefficient of multiple agreement $(\mathrm{Km})$ and associated statistics for a representative set of observed frequencies (Summer/fall fire, 6 raters).

\begin{tabular}{lcccc}
\hline \hline \multirow{2}{*}{ Case $(\mathbf{k})$} & \multicolumn{3}{c}{ Class } & \\
\cline { 2 - 5 } & $\mathrm{i}=1$ & $\mathrm{i}=2$ & $\mathrm{i}=3$ & $\mathrm{P}_{\mathbf{k}}$ \\
\hline 1 & 1 & 3 & 2 & 0.267 \\
2 & 2 & 4 & 0 & 0.467 \\
3 & 0 & 0 & 6 & 1 \\
4 & 0 & 2 & 4 & 0.467 \\
5 & 0 & 1 & 5 & 0.667 \\
6 & 0 & 0 & 6 & 1 \\
7 & 0 & 0 & 6 & 1 \\
8 & 1 & 1 & 4 & 0.400 \\
9 & 2 & 1 & 3 & 0.267 \\
\hline $\mathrm{a}_{\mathrm{i}}$ & 6 & 12 & 36 & $\mathrm{a} . .=54$ \\
\hline $\mathrm{p}_{\mathrm{i}}$ & 0.111 & 0.222 & 0.667 & p. $=1$ \\
\hline
\end{tabular}

$\mathrm{p}_{e}=\sum_{i=1}^{m} p_{i}^{2}=0.111^{2}+\ldots+0.667^{2}=0.506$

$p_{1}=\frac{\sum_{i=1}^{m} a_{i 1}\left(a_{i 1}-1\right)}{n(n-1)}=\frac{1(1-1)+\ldots+2(2-1)}{6(6-1)}=0.267$

$\mathrm{p}_{1}=\frac{\sum_{\mathrm{k}=1}^{N}}{N}=\frac{0.267+\ldots+0.267}{9}=0.615$

$\hat{\mathbf{K}}=\frac{\mathrm{p}_{\mathrm{m}}-\mathrm{p}_{\mathrm{e}}}{1-\mathrm{p}_{\mathrm{e}}}=\frac{0.615-0.506}{1-0.506}=0.220$

$\mathrm{P}_{\mathrm{ml}}=\frac{\sum_{k=1}^{N} \mathrm{a}_{i k}^{2}=N n p_{1}}{\mathrm{Nn}(\mathrm{n}-1) \mathrm{p}_{1}}=\frac{\left(1^{2}+\ldots+2^{2}\right)-(9 \times 6 \times 0.111)}{9 \times 6 \times 5 \times 0.111}=0.133$

$\hat{\mathbf{K}}_{\mathrm{ml}}=\frac{0.133-0.111}{1-0.111}=0.025$

Similarly: $\hat{K}_{\mathrm{m} 2}=0.143$ and $\hat{K}_{\mathrm{m} 3}=0.367$

The probability of observing any combination of ratings was calculated as if originated from a trinomial distribution. This was done for cases involving at least 2 and up to 7 raters. If $D, U$, and I are the 3 possible classes, then:

$$
p\left(D=x_{1}, \quad U=x_{2}, I=x_{3}\right)=r ! \underset{i=1}{\pi} \frac{p_{i}^{x i}}{x_{i}} !
$$

where $p(\bullet)$ indicates probability, $p_{i}$ is the probability of observing the corresponding $i$ class ( $p_{i}$ values add up to 1 , as usual), the $x_{i}$ 's are non-negative integers representing the distribution of ratings (e.g., $x_{1}=5, x_{2}=1$, and $x_{3}=0$ for a species receiving 6 ratings, 5 as $D$ and 1 as $U$ ), $r$ (varying from 2 to 7 ) is the sum of the $x_{i}$ (i.e., the number of raters involved in a particular judgment), $r$ ! stands for the factorial of $r$, and the symbol $\pi$ indicates the operation of multiplying together the indicated terms. The number of possible outcomes (i.e., combinations of ratings) for a given number of raters can be calculated as $(r+1)(r+2) / 2$ (e.g., 15 possible outcomes when 4 raters produce opinion). The total number of possible outcomes, considering that 2 and up to $n$ raters may be involved in one particular judgment, can be obtained from: 
Table 3. Possible outcomes (indicated as Decrease-Unaffected-Increase), probability of observing a given outcome by chance (p), probability of observing such an outcome or one more shifted toward $\mathrm{D}(\mathrm{pD})$ or toward $\mathrm{U}(\mathrm{pU})$ by chance, and corresponding classification.

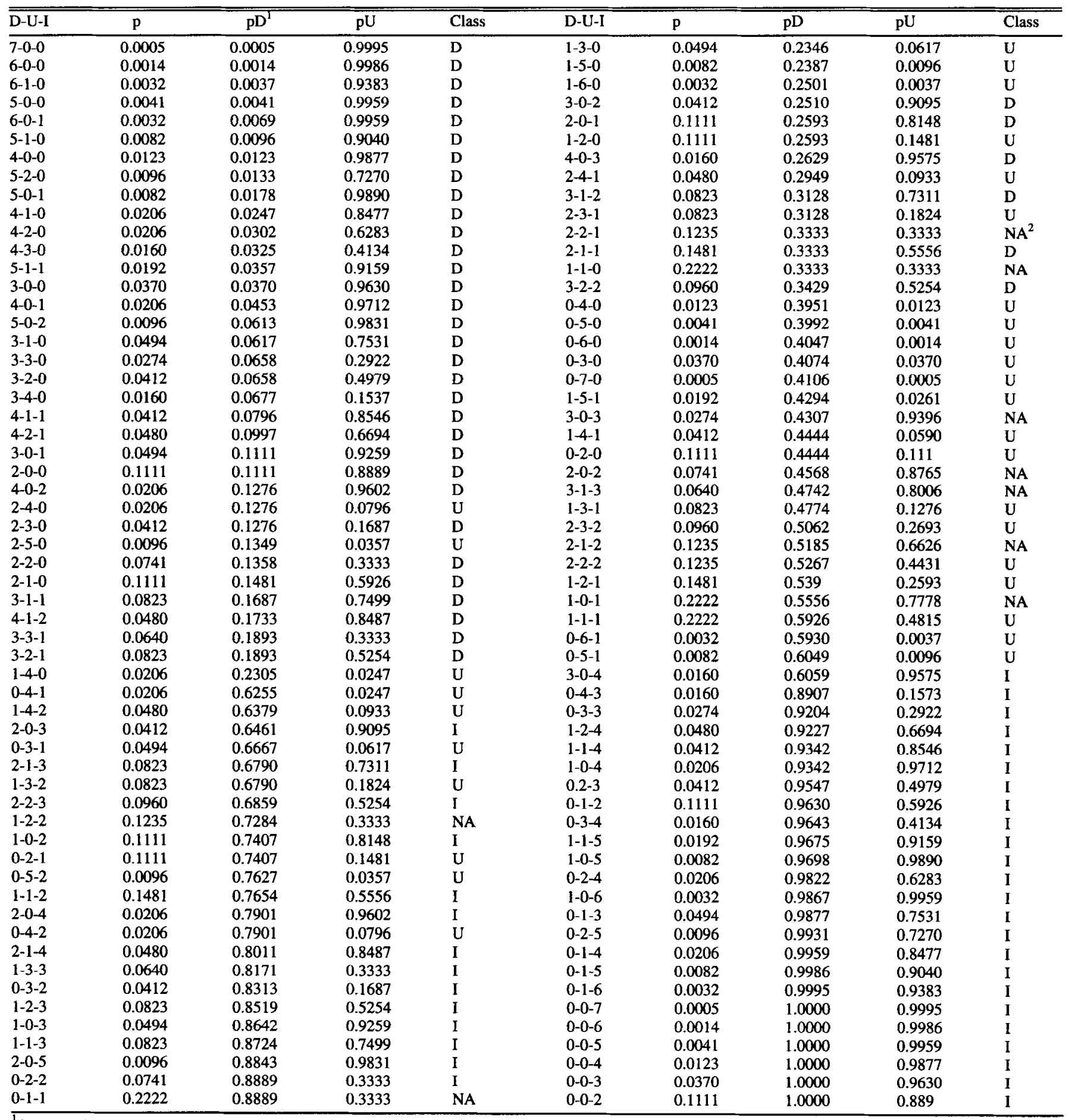

${ }_{2}^{1}$ Corresponding pI values can be read from $\mathrm{pD}$ columns by inverting the ordering of ratings (i.e., turning 4-1-0 into 0-1-4).

NA, classification is ambiguous, i.e., same minimum cumulative probability for more than 1 class.

$$
\sum_{r=2}^{n} \frac{(r+1)(r+2)}{2}
$$

and it equals 116 for $n=7$ (see first and sixth columns in Table 3 )..

Each one of those 116 possible outcomes has an associated probability of occurring by chance. Those probabilities can be calculated using equation [1] and they are shown in the second and seventh columns of Table 3 . Thus, observing 7 raters agreeing on the same rating (e.g., 7-0-0) is a rather improbable event ( $p$ $=0.0005$; Table 3 ) but so is observing 5 raters agreeing on the $D$ class and 2 other raters agreeing on the I class (i.e., a 5-0-2 outcome with associated probability $p=0.0096$; see Table 3 ). In 
fact, like in any lottery, the occurrence of any single outcome is rather improbable. Distinguishing agreement requires consideration of the probability of observing a distribution of ratings shifted toward any of the classes (e.g., 5-2-0) plus the probability of observing even more extreme outcomes (e.g., 6-1-0 and 7-0-0).

For each possible outcome when 2 and up to 7 raters were involved, the probability of observing such an outcome or one more extreme was calculated by addition. These cumulative probability distributions were then merged across number of ratings received (i.e., 2 to 7 ) to produce common cumulative probability distributions which included the 116 possible rating combinations. The assessment of what constitutes a "more extreme" combination of ratings in an ordinal setting depends upon the kind of weighting applied to the classes for evaluating "extremeness". If classes are linearly weighted (e.g., $1 x_{1}+2 x_{2}+3 x_{3}$ ), a species receiving 5,1 , and 1 opinions favoring $D, U$, and $I$, respectively, will be more extreme (i.e., more shifted towards the D class) than a species receiving 3,4 , and 0 opinions for the same class ordering. However, if a non-linear weighting is used (e.g., cubic weighting: $1^{3} x_{1}+2^{3} x_{2}+3^{3} x_{3}$ ), the ordering of these 2 combinations may be reversed because a larger weight is then attached to the single opinion in the I class (i.e., $x_{3}$ ) in the 5-1-1 combination. Results reported in this paper are based on a linear weighting of opinions because there was no reason to do otherwise. However, various weightings were tested and weightings as extreme as cubic or cubic root did not affect the graphical patterns of discrimination described in the Results section.

Since our objective was to discriminate between 3 classes, one of them (U) intermediate between the others, 3 different cumulative probability distributions were required, one for each class. Table 3 reproduces the cumulative probability distributions for D and $U$ classes when $p_{i}=p_{j}=1 / 3$ for every $i$ and $j$ (see $3^{\text {rd }}$ and $4^{\text {th }}$, and $8^{\text {th }}$ and $9^{\text {th }}$ columns in Table 3 ). Assuming that $p_{i}=p_{j}$ for every $\mathrm{i}$ and $\mathrm{j}$ implies that no previous knowledge is available on the distribution of plant species to classes for the set of plant species considered. When all $p_{i}$ are the same (i.e., 1/3), cumulative probability values for I can be obtained from the cumulative probability distribution for class $D$ by simply inverting the ordering of ratings (i.e., 4-1-0 favoring D turns into 0-1-4 in the I cumulative probability distribution). For some possible outcomes involving lack of agreement (e.g., 2-2-1, 1-1-0, 3-0-3) cumulative probabilities are the same for more than 1 class and therefore discrimination among alternative classes is not possible (see "NA" values in Table 3 ).

A sample of the calculations performed to produce the third entry in Table 3 will illustrate the procedure. If we assume that $p_{i}$ $=p_{j}=1 / 3$ for every $i$ and $j$, then according to [1] above:

$$
\begin{gathered}
\mathrm{p}(\mathrm{D}=6, \mathrm{U}=1, \mathrm{I}=0)=7 !\left[(1 / 3)^{6} / 6 !\right]\left[(1 / 3)^{1} / 1 !\right] \\
{\left[(1 / 3)^{0} / 0 !\right]=0.00320}
\end{gathered}
$$

which is the $p$ value for a 6-1-0 outcome as shown in Table 3. To obtain $\mathrm{pD}_{(6-1-0)}$ (i.e., the probability of observing such an outcome or one more shifted towards the $\mathrm{D}$ class) it is necessary to add up the probability of observing even more extreme combinations of ratings. In this case, the only more extreme alternative is 7-0-0 which has a probability of occurring by chance (calculated using (9) as shown above) equal to 0.00046 . Thus: $-\mathrm{pD}_{(6-1-0)}=$ $0.00320+0.00046=0.0037$-as indicated in Table 3. The same procedure would have to be applied to obtain $\mathrm{pU}_{(6-1-0)}$.
However, many more terms will have to be summed in this latter case because there are many combinations of ratings more shifted towards the $U$ alternative (e.g., 5-2-0, 4-3-0, 3-4-0) between 6-10 and the extreme $0-7-0$ combination which defines complete agreement on the $U$ class.

The $5^{\text {th }}$ and $10^{\text {th }}$ columns in Table 3 show the classification that any rating combination should receive according to the calculated cumulative probability distributions. Thus, a species receiving a 3-2-1 rating should be classified as $\mathrm{D}$ because $\mathrm{pD}=0.1893$ while $\mathrm{pU}=0.5254$ and $\mathrm{pI}=0.8519$ (i.e., $\mathrm{pD}$ for a $1-2-3$ rating equals 0.8519 ). The uncertainty of this classification, however, mainly depends on the smaller of those $p$ values. When a species with a 3-2-1 rating is classified as D we are accepting that such an outcome may occur by chance in about $19 \%$ of the cases. Controlling the uncertainty of the classification requires the selection of a probability threshold. This threshold represents the probability of accepting the classification as emerging from agreement among the raters when, in reality, it simply happened by chance. Of course, we would like to chose a probability threshold as low as possible but still compatible with producing some discrimination among plant species. If the cumulative probability for a given outcome is below the threshold in one of the cumulative probability distributions (e.g., D) but above it in the other 2 (i.e., $U$ and I), the species in question will be unambiguously classified (i.e., in that case, as a decreaser) at the selected probability level. This is the best-case scenario but 2 other alternatives are possible. First, the cumulative probability for a given combination of ratings may be below the threshold level in more than one of the distributions. In this case, membership in one class (i.e., the 1 above the threshold) would be ruled out, but membership in any of the other 2 classes would still be deemed possible at the probability level set for the threshold. Second, the corresponding cumulative probability for a certain outcome may be above the threshold level in all 3 distributions. This means that, for some threshold probability levels, the class to which the species in question most probably belongs could not be determined. Thus, the total number of plant species that could be unambiguously assigned to classes will depend on the probability threshold chosen.

Plotting the proportion of plant species discriminated as $\mathrm{D}, \mathrm{U}$, or I at different probability levels offers a visual appraisal of the consequences of the observed pattern of agreement and allows for the selection of a probability threshold. Patterns of expected discrimination and expected discrimination under perfect agreement can also be graphically represented for comparative purposes. Expected patterns can be calculated by weighting the probability of observing any of the possible outcomes (Table 3) according to the observed $\mathrm{p}_{i}$ 's and to the observed distribution of species across number of ratings. Estimates of the probabilities of occurrence of $D, U$, and I classes (i.e., $P_{i}$ 's) were calculated from totals across species recorded for each of the 6 scenarios (see Table 4). Thus, $p(D)$ for the No grazing scenario, for example, was estimated as 0.21 (i.e., 212/989 from Table 4). The distribution of species across number of ratings is also shown in Table 4. Patterns of expected discrimination under perfect agreement can be obtained in a similar way; only rating combinations that would show complete agreement (e.g., 0-7-0,3-0-0) are considered in this case. These latter patterns represent the expected situation under perfect agreement which may or may not be the situation that would allow maximum discrimination among cases for a given probability threshold. 
Table 4. Distribution of ratings across classes (D: decrease, $U$ : unaffected, 1 ; increase) and distribution of plant species across number of ratings per species for 6 management scenarios in the Edwards Plateau (Texas).

\begin{tabular}{|c|c|c|c|c|c|c|c|c|c|c|c|}
\hline \multirow[b]{2}{*}{ Scenario } & \multicolumn{3}{|c|}{ Class } & \multirow[b]{2}{*}{$\begin{array}{l}\text { Total } \\
\text { ratings }\end{array}$} & \multicolumn{6}{|c|}{ Ratings/species } & \multirow[b]{2}{*}{$\begin{array}{l}\text { Total } \\
\text { species }\end{array}$} \\
\hline & D & $\mathbf{U}$ & I & & 7 & 6 & 5 & 4 & 3 & 2 & \\
\hline No grazing & 212 & 398 & 379 & 989 & 41 & 47 & 44 & 29 & 15 & 17 & 193 \\
\hline $\begin{array}{c}\text { Moderate } \\
\text { grazing }\end{array}$ & 162 & 592 & 233 & 987 & 40 & 49 & 42 & 30 & 13 & 20 & 194 \\
\hline Heavy grazing & 456 & 191 & 336 & 983 & 39 & 47 & 44 & 31 & 14 & 19 & 194 \\
\hline No fire & 34 & 254 & 226 & 514 & _- & 15 & 17 & 29 & 36 & 41 & 138 \\
\hline $\begin{array}{l}\text { Winter/spring } \\
\text { fire }\end{array}$ & 205 & 212 & 271 & 688 & 15 & 17 & 27 & 33 & 38 & 38 & 168 \\
\hline $\begin{array}{l}\text { Summer/fall } \\
\text { fire }\end{array}$ & 208 & 158 & 57 & 423 & - & 9 & 13 & 20 & 32 & 40 & 114 \\
\hline
\end{tabular}

\section{Results}

The 7 raters consulted produced a total of 4,584 opinions on 198 plant species concerning response to cattle grazing $(2,959)$, and response to fire $(1,625)$. One rater did not produce judgment on either the No fire nor the Summer/fall fire scenarios. The mean number of ratings per species calculated across raters varied widely with grazing scenarios almost doubling the number of ratings received by fire scenarios. This trend was consistent across raters. The distribution of species across number of ratings received was skewed toward opposite extremes in grazing vs. fire scenarios (Table 4), i.e., most plant species received comparatively higher numbers of ratings in grazing rather than in fire scenarios.

The number of species involved in pair-wise comparisons was fairly variable, around $\mathbf{1 0 0}$ for grazing scenarios and half that number for fire scenarios (Table 5). Estimated pair-wise coefficients of agreement were moderate for 2 scenarios (Heavy grazing and Winter/spring fire) and low for the rest (Table 5). The number of pair-wise $K$ coefficients greater $(P<0.05)$ than 0 (out of 21 possible) was $14,10,18$, and 21 for No grazing, Moderate grazing, Heavy grazing, and Winter/ spring fire, respectively, and 4 out of 15 possible for both No fire and Summer/fall fire. None of the negative $K$ coefficients estimated (4 in No grazing, 3 in Modcrate grazing, 1 in No fire, and 4 in Summer/fall fire) was found to be different $(P<0.05)$ from 0 . Fourteen out of $21 \mathrm{~K}$ coefficients not significantly different from 0 and 6 out of 7 negative estimates in the grazing scenarios involved one particular rater. Within the grazing and fire scenarios, marginal disagreement (i.e., d) was negatively associated with $\mathrm{K}$ (Table 5).
The hypothesis of no extra agreement in excess of that due to chance or baseline association between ratings (tested using likelihood ratio statistics in the log-linear models) was rejected ( $\mathrm{P}<$ 0.05 ) in $16,9,14$, and 19 pair-wise cases out of 21 for No grazing, Moderate grazing, Heavy grazing, and Winter/spring fire, respectively. That hypothesis was only rejected $(\mathrm{P}<0.05)$ in 2 out of 15 possible cases in both the No fire and the Summer/fall fire scenarios.

For grazing scenarios, most of the agreement between raters (mean contributions \pm S.D.) was due to agreement in D $(0.28 \pm$ 0.23 to $0.50 \pm 0.08)$ and $I(0.41 \pm 0.07$ to $0.47 \pm 0.09)$ classes with a lower contribution from agreement in unaffected species $(0.09 \pm 0.12$ to $0.28 \pm 0.20)$. Similar results were observed for Winter/spring fire, but for No fure and for Summer/fall fire there were significant contributions from the $U$ class $(0.34 \pm 0.09$ and $0.37 \pm 0.17$, respectively) and low contributions from $D$ (No fire: $0.12 \pm 0.14$ ) and $I$ (Summer/ fall fire: $0.14 \pm 0.17$ ) classes.

The proportion ( \pm S.D.) of species classified as D by one rater and as I by another, in relation to the total number of species included in each pair-wise assessment, averaged $0.08( \pm 0.08)$ across scenarios and was generally low for each of the 6 scenarios. In contrast, $81 \%$ of the disagreement originated in comparisons including the intermediate $U$ class. The mean proportion of species classified in exactly the same class in pair-wise comparisons ranged from 0.43 for No fire to 0.63 for Winter/spring fire.

Results from the multiple-rater approach are shown in Table 6. Estimated coefficients were in general moderate to low with some examples of lack of agreement (negative point estimates that were not different from $0 ; P>0.05$ ). Agreement on assign-

Table 5. Pair-wise analysis of agreement. Number of species involved in pairs (N), kappa coefficient of agreement (K), and marginal disagreement (d). Results are for 6 management scenarios in the Edwards Plateau (Texas).

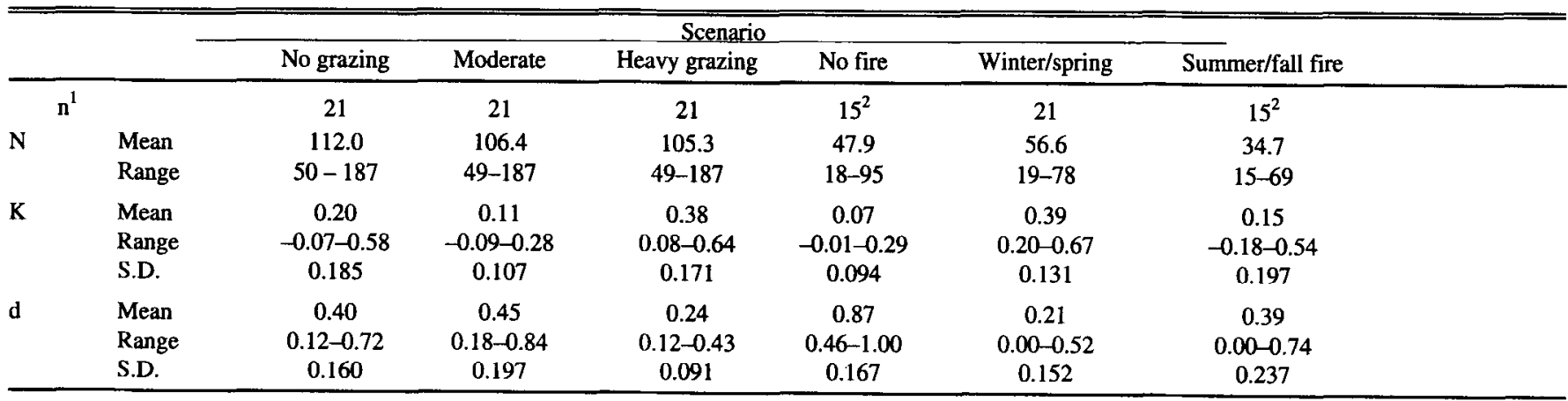

${ }_{3}^{1}$ Number of values (i.e., $\mathrm{N}, \mathrm{K}, \mathrm{d}$ ) included in the calculations of mean, range, and S.D.

${ }^{2}$ One of the experts did not produce opinion on No fire nor Summerffall fire. 
Table 6. Kappa coeficients of multiple agreement $(\mathrm{Km})$ calculated across number of ratings received per plant species (N). Results are for 6 management scenarios in the Edwards Plateau (Texas).

\begin{tabular}{|c|c|c|c|c|c|c|c|c|c|c|c|c|}
\hline \multirow[b]{3}{*}{$\mathbf{N}$} & \multicolumn{12}{|c|}{ Scenario } \\
\hline & \multicolumn{2}{|c|}{ No grazing } & \multicolumn{2}{|c|}{ Moderate } & \multicolumn{2}{|c|}{ Heavy grazing } & \multicolumn{2}{|c|}{ No fire } & \multicolumn{2}{|c|}{ Winter/spring } & \multicolumn{2}{|c|}{ Summer/fall fire } \\
\hline & $n^{1}$ & $\mathrm{~K}_{\mathrm{m}} \pm \mathrm{S} . \mathrm{E}$ & $\mathbf{n}$ & $K_{m} \pm S . E$. & $\mathrm{n}$ & $K_{m} \pm S . E$. & $\mathbf{n}$ & $K_{\mathrm{m}} \pm \mathrm{S} . \mathrm{E}$. & $\mathbf{n}$ & $\mathrm{K}_{\mathrm{m}} \pm \mathrm{S} . \mathrm{E}$ & $\mathbf{n}$ & $\mathrm{K}_{\mathrm{m}} \pm$ S.E. \\
\hline 7 & 41 & $.22 \pm .031 *^{2}$ & 40 & $06 \pm .035$ & 39 & $.40 \pm .044^{*}$ & & -3 & 15 & $.53 \pm .058^{*}$ & & -3 \\
\hline 6 & 47 & $.19 \pm .030^{*}$ & 49 & $11 \pm .047^{*}$ & 47 & $.40 \pm .032 *$ & 15 & $-.02 \pm .087$ & 17 & $.39 \pm .088^{*}$ & 9 & $.22 \pm .143$ \\
\hline 5 & 44 & $.23 \pm .041^{*}$ & 42 & $11 \pm .078$ & 44 & $.33 \pm .039 *$ & 17 & $-.10 \pm .077$ & 27 & $.31 \pm .045^{*}$ & 13 & $-.04 \pm .063$ \\
\hline 4 & 29 & $.21 \pm .062 *$ & 30 & $08 \pm .090$ & 31 & $.17 \pm .054 *$ & 29 & $.03 \pm .073$ & 33 & $.24 \pm .053^{*}$ & 20 & $.10 \pm .084$ \\
\hline 3 & 15 & $.20 \pm .117$ & 13 & $-.14 \pm .261$ & 14 & $.16 \pm .139$ & 36 & $.03 \pm .097$ & 38 & $.17 \pm .070^{*}$ & 32 & $.19 \pm .100$ \\
\hline 2 & 17 & $.46 \pm .174^{*}$ & 20 & $-.13 \pm .229$ & 19 & $.06 \pm .065$ & 41 & $-.17 \pm .144$ & 38 & $-.09 \pm .132$ & 40 & $.14 \pm .134$ \\
\hline
\end{tabular}

Number of plant species.

${ }_{3}^{2} K_{m}$ greater $(p<0.05)$ than 0

${ }^{3}$ One of the experts did not produce opinion on no fire or summer/fall fire.

ments to individual classes showed similar trends to those observed in the analysis of contribution of different classes to pair-wise agreement. Among cases exhibiting significant agreement (Table 6), agreement on the D class varied from 0.21 (Moderate grazing, 6 ratings) to 0.61 (Winter/spring fire, 7 ratings) with a mean value $( \pm$ S.D.) of $0.39( \pm 0.127)$. For the I class, agreement varied from 0.12 (Moderate grazing, 6 ratings) to 0.71 (Winter/spring fire, 7 ratings) with a mean value of 0.33 $( \pm 0.156)$. Agreement on the $U$ class ranged from -0.06 (Winter/spring fire, 3 ratings) to 0.63 (No grazing, 2 ratings) with a mean value of 0.12 ( \pm 0.166$)$. For Heavy grazing and Winter/spring fire, multiple agreement increased with the number of ratings received per species (Table 6).

Expected and observed patterns of discrimination among classes, according to the probability threshold selected, and expected patterns of discrimination under perfect agreement (i.e., when only combinations that show complete agreement are considered, e.g., 0-7-0, 3-0-0) are shown in Figure 1. Observed patterns of discrimination for different scenarios can be compared with the corresponding expected patterns under chance agreement among raters. In all scenarios, the performance of the raters, in terms of proportion of species discriminated into classes, was above chance expectations for probability levels below 0.2 to 0.4 (Fig. 1). Only for the Heavy grazing scenario was discrimination consistently above chance expectations over the entire probability range. The 2 scenarios with a maximum of only 6 ratings per species (No fire and Summer/fall fire) showed discrimination patterns close to (Summer/fall fire) or below (No fire) chance expectations at probability levels above 0.3 . A similar pattern was observed in the Moderate grazing scenario. For $p<0.2$ the observed pattern of discrimination was about mid-way between chance expectation and expected discrimination under perfect agreement for all scenarios, except for No fire and Summer/fall fire.

Table 7 shows, for each scenario, numbers of species assigned to classes on the basis of setting the threshold probability value at 0.15 . Table 8 contains some classification examples. About $80 \%$ of the species was classified in grazing scenarios in contrast to only 40 to $60 \%$ in fire scenarios (Table 7). Species classification and associated probabilities should be interpreted in the context of expert opinion elicitation. An I classification with associated probability of 0.032 for whitebrush in the Moderate grazing scenario (first entry in Table 8), for example, means that the probability of observing a group of experts agreeing by chance when classifying the species as an increaser under moderate grazing is about 3 in a hundred. Probability values in Table 8 also show that agreement was notably higher for grazing than for fire scenarios and fairly variable across species.

\section{Discussion}

The kind of factual knowledge elicited and analyzed in this work is declarative (e.g., species A will decrease under heavy cattle grazing) as opposed to procedural (e.g., if there is heavy cattle grazing, then highly palatable caespitous tall grass species will tend to decrease; given that $\mathrm{A}$ is a highly palatable tall grass, it will decrease). The usual approach to expert knowledge utilization normally focuses on mimicking expert reasoning by developing rules based on previously elicited procedural knowledge. An alternative approach for vegetation change prediction (Rodríguez Iglesias 1996) involves gathering declarative expert knowledge conditional on some situation of interest (e.g., different grazing scenarios) and deriving the "procedural rules" from ecological attributes of the plant species involved, conditional on the responses predicted by the raters (a constraint imposed by the use of classification trees). Thus, rules emerge from agreement on plant species responses and classification of plant species into ecologically meaningful response groups. Rules can then be checked against the raters' procedural knowledge and available experimental results, and refined or updated as deemed necessary (Rodríguez Iglesias 1996).

The nature of the expertise implicated in this kind of knowledge use requires close examination. For the purpose of this work, expertise was role-suggested and it was not tested beforehand. The reason for this is the same that suggested the use of expert opinion in the first place: lack of experimental and/or systematically gathered comparative observational data on plant species responses. Thus, there are no standard sources against which experts' predictions could be checked, as is usually the

Table 7. Number of species classified when the probability threshold for agreement among experts is set to $\mathbf{0 . 1 5}$ (see text for further explanation). Results are for 6 management scenarios in the Edwards Plateau (Texas).

\begin{tabular}{lcccc}
\hline & \multicolumn{4}{c}{ Class } \\
\cline { 2 - 5 } Scenario & Decrease & Unaffected & Increase & Unclassified $^{1}$ \\
\hline No grazing & 39 & 73 & 44 & 42 \\
Moderate grazing & 24 & 32 & 101 & 41 \\
Heavy grazing & 79 & 56 & 16 & 47 \\
No fire & 3 & 57 & 39 & 99 \\
Winter/spring fire & 39 & 54 & 25 & 80 \\
Summer/fall fire & 49 & 2 & 23 & 124 \\
\hline
\end{tabular}

Species received less than 2 opinions, agreement between raters was below the selected probability threshold, or the classification was ambiguous, i.e., cumulative probability was the same for more than 1 class. 

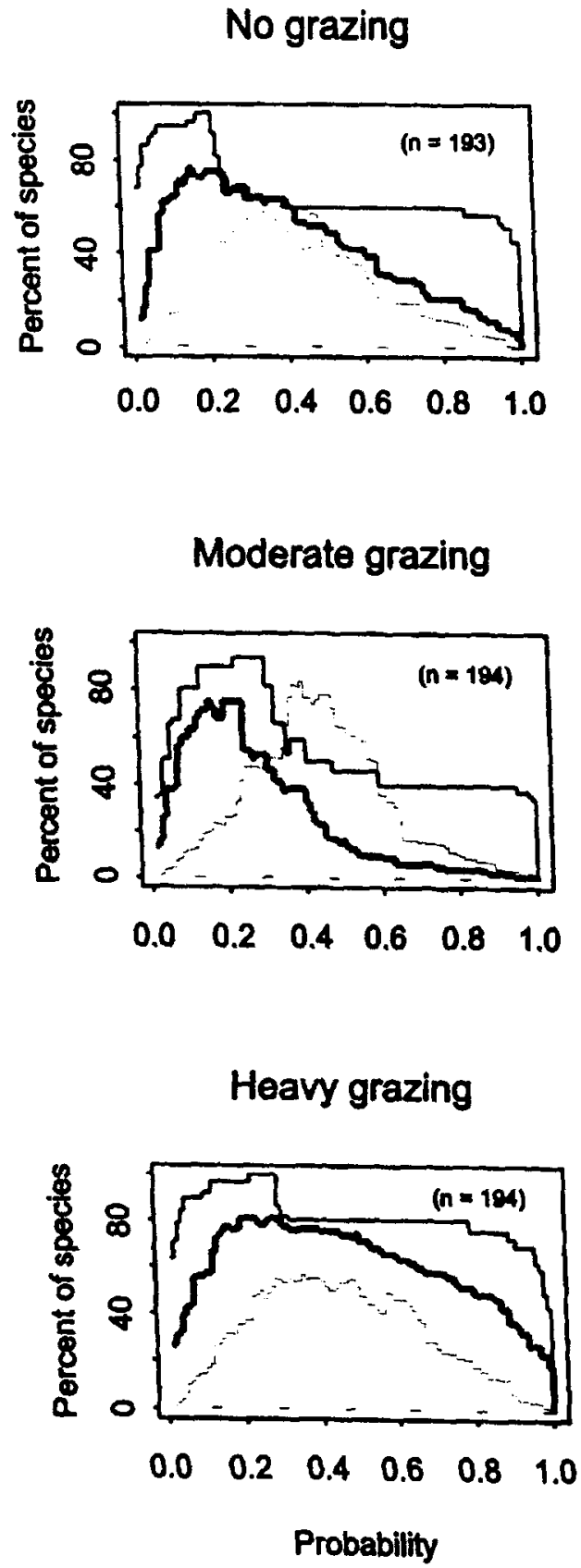

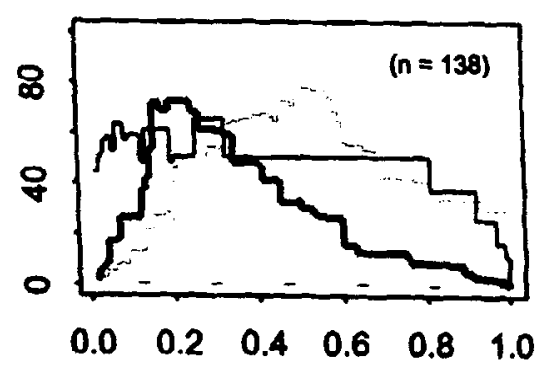

Winter/ spring fire

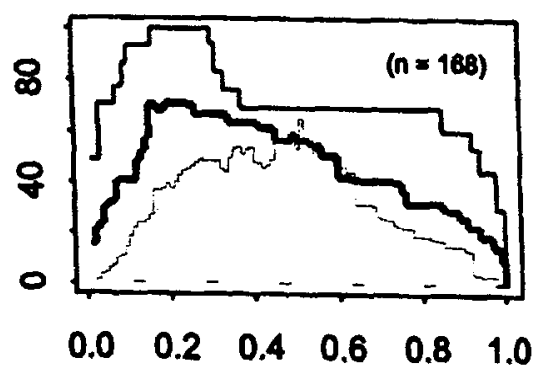

Summer/ fall fire

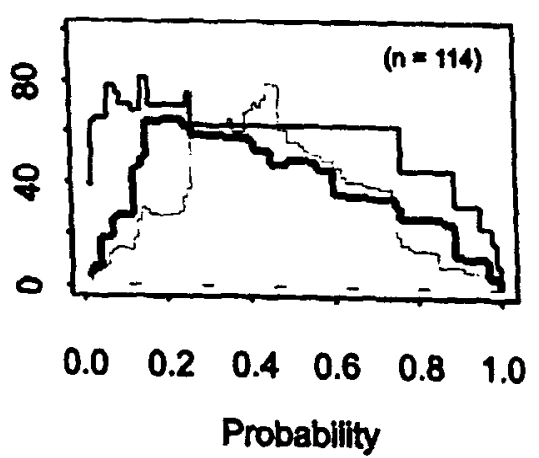

Fig. 1. Percent of species discriminated to classes (decrease, increase, unaffected) at different probability levels for 6 management scenarios in the Edwards Plateau (Texas). Patterns shown are those expected by chance (dotted line), expected under perfect agreement (narrow-solid line), and observed (wide-solid line). Total numbers of plant species are indicated in parentheses.

case in other domains (e.g., weather forecasting, financial analysis). In this context, agreement between experts is a necessary but not a sufficient condition to expect good performance for the ecological rules to be derived.

The lack of readily available feedback from the experts' domain has another important consequence. Bolger and Wright (1994) convincingly argued that judgment performance depends on 2 main characteristics: the degree of familiarity of the expert with the type of judgment she/he is being asked to produce and the likelihood of feedback which could be used to refine subsequent judgment. The first characteristic is termed ecological validity and depends on the kind of questions asked. The second one is called learnability and depends on the nature of the domain. Domain and procedures involved in this work correspond to a scenario of high ecological validity, i.e., experts were familiar with the kind of task proposed, and low to moderate learnability, i.e., the possibility of refining domain models of plant species responses from repeated feedback are scarce and fragmentary. For this kind of scenario, the Bolger and Wright (1994) approach would predict poor to moderately good judgmental performance in terms of accuracy and reliability. Unfortunately, there are no similar studies on plant species with 
Table 8. Examples of species classification (D: decrease, U: unaffected, I: increase) and associated probability (p) of arriving at the classification by chance. Results are for 6 management scenarios in the Edwards Plateau (Texas).

\begin{tabular}{|c|c|c|c|c|c|c|c|c|c|c|c|c|c|}
\hline & \multirow[b]{2}{*}{ Common name } & \multicolumn{2}{|c|}{$\begin{array}{c}\text { No } \\
\text { grazing }\end{array}$} & \multicolumn{2}{|c|}{$\begin{array}{c}\text { Moderate } \\
\text { grazing }\end{array}$} & \multicolumn{2}{|c|}{$\begin{array}{l}\text { Heavy } \\
\text { grazing }\end{array}$} & \multicolumn{2}{|c|}{ No fire } & \multicolumn{2}{|c|}{$\begin{array}{l}\text { Winter/ } \\
\text { spring fire }\end{array}$} & \multicolumn{2}{|c|}{$\begin{array}{l}\text { Summer } \\
\text { fall fire }\end{array}$} \\
\hline & & Class & p & Class & $\mathrm{p}$ & Class & $\bar{p}$ & Class & $\mathrm{p}$ & Class & $\mathbf{p}$ & Class & $\mathrm{p}$ \\
\hline $\begin{array}{l}\text { Aloysia gratissima (Gill. } \\
\text { \& Hook.) Troncoso } \\
\text { var. gratissima }\end{array}$ & Whitebrush & $\mathrm{I}$ & 0.068 & I & 0.032 & I & 0.013 & $\bar{I}$ & 0.010 & $\mathrm{D}$ & 0.189 & -1 & 0.333 \\
\hline Ambrosia artemisiifolia $\mathrm{L}$. & Ragweed & I & 0.313 & $\mathbf{I}$ & 0.080 & I & 0.001 & U & 0.111 & U & 0.148 & -1 & 0.333 \\
\hline $\begin{array}{l}\text { Bouteloua curtipendula } \\
\text { (Michx.) Torr. var. } \\
\text { curtipendula }\end{array}$ & Sideoats grama & I & 0.004 & U & 0.026 & $\mathrm{D}$ & 0.036 & I & 0.030 & I & 0.000 & $\mathrm{U}$ & 0.080 \\
\hline $\begin{array}{l}\text { Engelmannia pinnatifida } \\
\text { Nutt. }\end{array}$ & Engelmann daisy & $\mathbf{I}$ & 0.013 & $\mathrm{U}$ & 0.036 & $\mathrm{D}$ & 0.004 & I & 0.062 & $\mathrm{D}$ & 0.169 & $\mathrm{U}$ & 0.481 \\
\hline $\begin{array}{l}\text { Hilaria belangeri (Steud.) } \\
\text { Nash }\end{array}$ & Curlymesquite & $\mathrm{D}$ & 0.004 & I & 0.032 & I & 0.007 & $\mathrm{U}$ & 0.182 & I & 0.032 & -1 & 0.333 \\
\hline Juniperus ashei Buchholz & Ashe juniper & I & 0.032 & I & 0.004 & I & 0.004 & I & 0.001 & $\mathrm{D}$ & 0.000 & D & 0.001 \\
\hline $\begin{array}{l}\text { Opuntia lindheimeri } \\
\text { Engelm. var. lindheimeri }\end{array}$ & Texas pricklypear & I & 0.343 & I & 0.013 & I & 0.036 & I & 0.030 & $\mathbf{D}$ & 0.004 & $\mathrm{D}$ & 0.001 \\
\hline $\begin{array}{l}\text { Schizachyrium scoparium } \\
\text { (Michx.) Nash var. } \\
\text { frequens (C.E. Hubb.) Gould }\end{array}$ & Little bluestem & I & 0.004 & $\mathbf{U}$ & 0.093 & D & 0.000 & I & 0.189 & I & 0.000 & $\mathrm{I}$ & 0.128 \\
\hline $\begin{array}{l}\text { Stipa leucotricha Trin. } \\
\text { \& Rupr. }\end{array}$ & Texas wintergrass & I & 0.343 & I & 0.032 & D & 0.100 & $\mathrm{U}$ & 0.182 & $\mathrm{D}$ & 0.189 & D & 0.313 \\
\hline $\begin{array}{l}\text { Tripsacum dactyloides } \\
\text { (L.) L. }\end{array}$ & Eastern wheatgrass & I & 0.001 & D & 0.001 & D & 0.001 & I & 0.136 & I & 0.004 & $\mathrm{U}$ & 0.111 \\
\hline
\end{tabular}

Classification is ambiguous, i.e., cumulative probabilities are the same for more than 1 class.

${ }^{2}$ Species received less than 2 opinions for the particular scenario.

which to compare accuracy, reliability, or even observed agreement among experts.

Agreement calculated using $\mathrm{K}$ coefficients (Tables 5 and 6 ) should be considered a lower limit for the possible agreement attainable in this domain for various reasons. Kappa coefficients ignore any ordering in the classes and, in this particular case, most of the disagreement originated in contiguous classes. In addition, there were no attempls to train the raters before submitting the questionnaires. As observed in Table 5, marginal disagreement accounted for an important portion of the lack of agreement between raters in most scenarios. Kappa statistics are very sensitive to marginal disagreement; given marginal disagreement, Conger (1980) reported negative estimated $\mathrm{K}_{\mathrm{m}}$ 's for randomly generated data.

Training can improve distinguishability betwecn classes (sensu Darroch and McCloud 1986) thus reducing marginal disagreement. However, training would be probably ineffective in some circumstances (e.g., No fire or Summer/fall fire) in which the problem seems to be lack of knowledge rather than lack of agreement. This is evident when comparing the distribution of species according to number of ratings in grazing vs. fire scenarios (Table 4) and the total number of species that received at least 2 ratings (Table 4).

Another factor contributing to low agreement, particularly in No grazing and Heavy grazing scenarios, was the judgment produced by 1 of the experts. Figure 2 shows 2 - dimensional representations obtained by multidimensional scaling of the $21 \mathrm{~K}$ coefficients corresponding to the $n(n-1) / 2$ possible pair-wise combinations for $\mathrm{n}$ equal to 7 . Scaling of the matrix of $\mathrm{K}$ coefficients allows two-dimensional representations of similarities in judgment among the experts. The dimensions indicated in Fig. 2 are synthetic variables that effectively summarizes the pattern of agreement emerging from the total number of dimensions involved (i.e., the 198 plant species). In spite of the generally high dispersion of the information, it is clear that one of the raters showed up as an important source of lack of agreement. This is a point of concern, although a majority consensus does not necessarily indicate that the dissenting rater is the 1 producing poor judgment. She/he may be using different but still legitimate criteria to discriminate among classes. It should be stressed that the kind of task proposed to the raters in this work not only requires knowledge on the subjects (i.e., range plant species) but also on their potential behavior under selected states of nature. This endeavor is more complex than, for example, identifying pathologies based on symptoms and signs in the medical arena.

The overall pattern emerging from pair-wise and multi-expert analyses indicated that D and I classes justified most of the observed agreement. This, along with the marginal distributions of the expert opinion collected (Table 4), strongly suggests that the factors involved (i.e., intensity of grazing and season of burning) are indeed considered important sources of change in rangelands.

Results from pair-wise log-linear analyses were in agreement with the patterns observed in pair-wise $\mathrm{K}$ statistics comparisons. A log-linear multi-rater approach was not feasible for the data sets included in this work due to a combination of size and sparseness of the classifications. In general in a multi-rater loglinear approach, models have to be fit to sparse data sets containing $\mathrm{m}^{\mathrm{n}}$ number of cases, where $\mathrm{m}$ is the number of classes and $\mathrm{n}$ the number of raters. 


\section{No grazing}

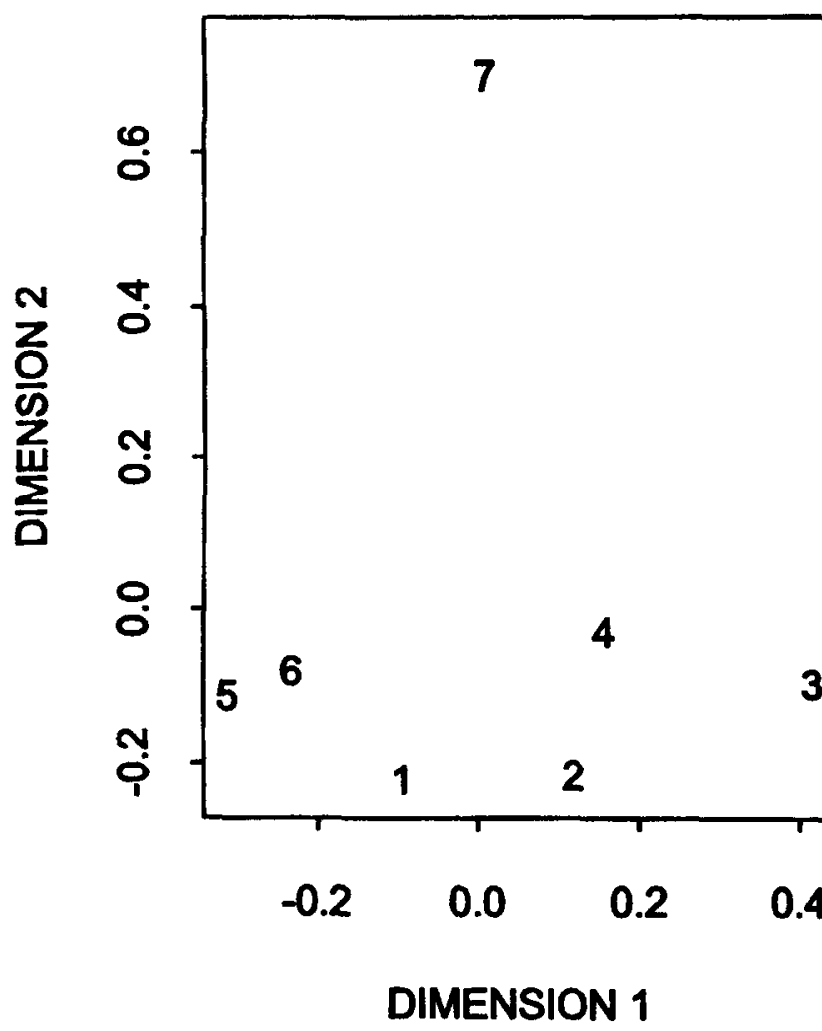

Fig. 2. Bidimensional plots of multidimensional scaling distances calculated among 7 raters for 2 different management scenarios in the Edwards Plateau (Texas). Dimensions 1 and 2 summarize (dis)similarities among judgments for the complement of plant species considered.

Interpretation of Figure 1 requires some background considerations. Expected patterns of discrimination under chance agreement among raters depend on observed probabilities of occurrence for each class (i.e., $\mathrm{p}_{i}$ 's), which varied for different scenarios (Table 4), and on the distribution of species across number of ratings (Table 4), also variable among scenarios. The proportion of species that can be discriminated is maximized for intermediate probability values. This is due to the location of the probability threshold relative to the cumulative probability distributions. If this threshold is set close to 1 , only a small proportion of species (i.e., those receiving a high number of agreeing ratings) would be discriminated. For the rest of the species, cumulative probability values would be below the threshold for all 3 classes. At intermediate probability levels, the number of species that can be discriminated increases because more species can be unambiguously assigned to one class even with fewer numbers of ratings. As the probability threshold approaches 0 , the proportion of species that can be discriminated decreases again because, for most species, the cumulative probability for any of the classes will then be above the probability threshold.

Similar considerations are valid for interpreting observed patterns of discrimination. Skewed patterns (e.g., as in Moderate grazing or No fire) indicate that some extreme rating combina- tions (e.g., 7-0-0, 6-0-0), which would allow species discrimination at high and intermediate probability levels, are underrepresented. This means that the agreement observed in those scenarios was comparatively weaker than the agreement observed in the Heavy grazing or Winter/spring fire scenarios. The range of low probability values is the most relevant because the lower the probability threshold chosen, the higher the confidence in a correct classification. For a fixed number of raters, there is a tradeoff situation in which the objective is to maximize the number of discriminated species, conditional on a certain confidence in the classification performed. For the collected data set, threshold values below about 0.20 would be the ones to be considered for any scenario (Fig. 1). Thus, choosing a probability threshold between 0.1 and 0.2 would be a reasonable compromise between maximizing the number of classified species and minimizing uncertainty in the agreement-based classification (Fig. 1). More agreement among experts or the use of more experts of similar ability (i.e., of comparable competence at distinguishing among classes) would allow an increase in confidence (i.e., similar discrimination at lower probability levels) or in the proportion of classified species (i.e., better discrimination capabilities for a fixed probability threshold).

Discrimination at low probability levels was generally weaker in fire than in grazing scenarios. This was due in part to lack of agreement (e.g., No fire or Summer/fall fire scenarios; Fig. 1) but, more generally, due to lack of knowledge (see marginals in Table 4). Not surprisingly, agreement among raters was better (Tables 5 and 6) and pattern of agreement more consistent (Fig. 1) when scenarios were most familiar to the experts, like heavy cattle grazing and winter/spring burning. It is not clear whether the lack of agreement in Moderate grazing (Table 5; Fig. 1) resulted from difficulties in distinguishing the intermediate $U$ class (presumably more frequent in this scenario) from the other 2 , or from disagreement on the consequences of moderate grazing. Agreement on the U class in the Moderate grazing scenario $(0.28 \pm 0.20$; mean contribution \pm S.D.) was relatively low and marginal disagreement was relatively high (Table 5). This suggests that lack of agreement probably resulted from different views on the consequences of moderate cattle grazing or on what every expert considered "moderate" grazing. Specific applications will indeed be more restrictive in terms of type of vegetation considered and more precise in the definition of possible scenarios. These conditions can be expected to produce more homogeneous marginal distributions of ratings, possibly improving agreement.

In spite of the limited number of species successfully classified in the fire scenarios (Table 7), 2 trends are worth noting. Only very reduced numbers of species are classified as either decreasing under No fire or unaffected under Summer/fall fire. The first trend seems to indicate that the absence of fire is visualized as a generally permissive condition for increases in plant species abundance. The contrast in the number of species classified as $U$ in Winter/spring fire and Summer/fall fire, on the other hand, is probably a reflection of the widely held opinion that winter/spring fires involve less energy generation (i.e., they are "cooler") than summer/fall fires.

Landis and Koch (1977) proposed a majority rule to differentiate cases according to agreement. The cumulative probability approach developed in this paper differs from a majority rule in 2 important aspects. It accounts for the ordinal nature of the information and, given a selected probability threshold, it provides an objective criterion for classification. 
One important caveat relative to the use of declarative expert information is the degree of common knowledge. Experts usually draw knowledge from common sources and reasoning by analogy with the case of a statistical linear model, it is easy to visualize that this should induce some degree of correlation among expert judgments. The log-linear approach used in this work accounts for such a baseline association, but the trinomial model proposed for species classification assumes that opinions from different raters are independent. This may inflate confidence in the classification, or induce unwarranted discrimination among classes in some plant species. However, bias is not to be expected because the effect (if any) would be spread throughout the classification.

\section{Conclusions}

- Low to moderate agreement on plant species responses to cattle grazing and fire was observed among 7 experts familiar with vegetation processes in the Edwards Plateau (Texas). This is in agreement with the low learnability of the domain.

- Agreement was better and pattern of agreement more consistent when scenarios were most familiar to the experts (e.g., winter/spring burning).

- The use of different criteria for distinguishing among classes (i.e., different marginal distributions) seems to be a significant source of lack of agreement.

- Marginal disagreement could be reduced with training and it can be expected to be less significant for more specific (i.e., local) scenarios and vegetation compositions (i.e., on simplified domains).

- Lack of information, rather than lack of agreement, seems to be the cause for the poor agreement observed in No fire and Summer/fall fire scenarios.

- A procedure was developed that uses cumulative probability distributions to establish an objective criterion for identifying agreement among experts in ordinal scale. Graphical representations help to understand and evaluate relationships between the number of expert sources and their ability to distinguish among classes for a previously chosen accuracy.

\section{Research and Management Implications}

We emphasize that agreement rather than expertise was evaluated in this work. Feasible methods are needed to facilitate the evaluation of expertise in a domain characterized by moderate to low learnability.

Expert judgment, standardized in a meaningful format, can be a viable alternative for knowledge acquisition when field trials or surveys are not cost-effective (Kadane et al. 1980). This kind of information could also be used to identify research/survey needs, to characterize areas of (dis)agreement in plant species behavior (e.g., Table 8) that may require special attention, traits associated with plant responses, and/or factors affecting responses. The use of declarative expert knowledge would be particularly helpful to fill information gaps on comparative attributes which are expensive or difficult to evaluate experimentally (e.g., this work, Phillips et al. 1996, Rodríguez Iglesias and Kothmann 1998). Opportunities for refining domain models from repeated feedback are scarce and fragmentary. This situation should encourage an integral use of domain knowledge including, although not limited to, the elicitation of expert opinion from qualified individuals. New ways of reducing uncertainty should be explored including the use of subjective probabilities incorporated as prior information destined to be updated as the knowledge base becomes enriched with new experimental/survey data. In a more general way, empirical approaches based upon expert information may prove valuable in providing management decision support where such information would be difficult or unfeasible to generate from purely experimental alternatives.

\section{Literature Cited}

Agresti, A. 1988. A model for agreement between ratings on an ordinal scale. Biometrics 44:539-548.

Agresti, A. 1992. Modelling patterns of agreement and disagreement. Stat. Method Med. Res. 1:201-218.

Agresti, A. and J.B. Lang. 1993. Quasi-symmetric latent class models, with application to rater agreement. Biometrics 49:131-139.

Bolger, F. and G. Wright. 1994. Assessing the quality of expert judgment. Decision Support Syst. 11:1-24.

Botkin, D.B. 1974. Functional groups of organisms in model ecosystem. pp. 98-101. In: S.A. Levin (ed.). Ecosystem analysis and prediction. Proceedings of a SIAM-SIMS Conference. Alta, Ut.

Chesson, P.L. and T.J. Case. 1986. Overview: nonequilibrium community theories: chance, variability, history, and coexistence. p. 229-239. In: J. Diamond and T.J. Case (eds.). Community ecology. Harper and Row, New York, N.Y.

Clements, F.E. 1920. Plant indicators: the relation of plant communities to process and practice. Carnegie Institution of Washington Publ. 298.

Cohen, J. 1960. A coefficient of agreement for nominal classes. Educ. Psychol. Meas. 20:37-46.

Conger, A.J. 1980. Integration and generalization of kappas for multiple raters. Psychol. Bull. 88:322-328

Darroch, J.N. and P.I. McCloud, 1986. Category distinguishability and observer agreement. Aust. J. Stat. 28:371-388.

Dawid, A.P., M.H. DeGroot, and J. Mortera. 1995. Coherent combination of experts' opinions. Test 4:263-313.

DeAngelis, D.L. and J.C. Waterhouse. 1987. Equilibrium and nonequilibrium concepts in ecological models. Ecol. Monogr. 57:1-21.

Dyksterhuis, E.J. 1949. Condition and management of rangeland based on quantitative ecology. J. Range Manage. 2:104-115.

Dyksterhuis, E.J. 1958. Range conservation as based on sites and condition classes. J. Soil Water Conserv. 13:151-155.

Fleiss, J.L. 1971. Measuring nominal scale agreement among many raters. Psychol. Bull. 76:378-382.

Fleiss, J.L., J. Cohen, and B.S. Everitt. 1969. Large sample standard errors of kappa and weighted kappa. Psychol. Bull. 72:323-327.

Genest, C. and J.V. Zidek. 1986. Combining probability distributions: a critique and annotated bibliography. Stat. Sci. 1:114-148.

Gleason, H.A. 1926. The individualistic concept of the plant association. Bull. of the Torrey Bot. Club 53:7-26.

Goodall, D.W. 1963. The continuum and the individualistic association. Vegetatio 11:297-316.

Goodman, L.A. 1979. Simple models for the analysis of association in cross-classifications having ordered categories. J. Amer. Stat. Assoc. 74:537-552.

Grime, J.P., J.G. Hodgson, and R. Hunt. 1988. Comparative plant ecology: a functional approach to common British species. Unwin Hyman, London, UK.

Johnson, H.B. and H.S. Mayeux. 1992. Viewpoint: a view on species additions and deletions and the balance of nature. J. Range Manage. 45:322-333.

Kadane, J.B. 1993. Several Bayesians; a review. 'Test 2:1-32.

Kadane, J.B., J.M. Dickey, R.L. Winkler, W.S. Smith, and S.C. Peters. 1980. Interactive elicitation of opinion for a normal linear model. J. Amer. Stat. Assoc. 75:845-854. 
Landis, J.R. and G.G. Koch. 1977. An application of hierarchical kappa-type statistics in the assessment of majority agreement among multiple observers. Biometrics 33:363-374.

Lee, J.J. and Z.N. Tu. 1994. A better confidence interval for kappa ( $\kappa$ ) on measuring agreement between two raters with binary outcomes. J Comput. Graph. Stat. 3:301-321.

McCullagh, P. and J.A. Nelder. 1989. Generalized linear models. Chapman and Hall, London, UK.

McIntosh, R.P. 1995. H.A. Gleason's "individualistic concept" and theory of animal communities: a continuing controversy. Biol. Rev. 70:317-357.

Phillips, R.L., N.K. McDougal, and J. Sullins. 1996. Plant preference of sheep grazing in the Mojave desert. Rangelands 18:141-144.

Rodríguez Iglesias, R.M. 1996. A formalism for characterizing vegetation responses using classification trees and Dempster-Shafer theory of evidence. Ph.D. Diss., Texas A\&M Univ.. College Station, Tex.

Rodríguez Iglesias, R.M, and M.M. Kothmann. 1997. Structure and causes of vegetation change in state and transition model applications. J. Range Manage. 50:399-408.

Rodríguez Iglesias, R.M., and M.M. Kothmann. 1998. Best linear unbiased prediction of herbivore preferences. J. Range Manage. 51:19-28.

Rodríguez Iglesias, R.M., M.G. Walsh, and M.M. Kothmann. 1998. Dealing with uncertainty: Bayesian belief networks for natural resources management and evaluation. (In preparation).
Sampson, A.W. 1917. Succession as a factor in range management. J. Forest. 15:539-596

Sampson, A.W. 1919. Plant succession in relation to range management. Bull. No. 791. US Dept. of Agr., Washington D.C.

Stat. Sci. Inc. 1993. S-Plus user's guide. Stat. Sci. Inc., Seattle, Wash.

Tanner, M.A. and M.A. Young. 1985. Modeling agreement among raters. J. Amer. Stat. Assoc. 80:175-180.

Uebersax, J.S., and W.M. Grove. 1993. A latent trait finite mixture model for the analysis of rating agreement. Biometrics 49:823-835.

Westoby, M., B. Walker, and I. Noy-Meir. 1989a. Opportunistic management for rangelands not at equilibrium. J. Range Manage. 42:266-274.

Westoby, M., B. Walker, and I. Noy-Meir. 1989b. Range management on basis of a model which does not seek to establish equilibrium. J. Arid Environ. 17:235-239.

Wiens, J.A. 1984. On understanding a non-equilibrium world: myth and reality in community patterns and processes. pp. 439-457. In: D.R. Strong Jr., D. Simberloff, L.G. Abele, and A. B. Thistle (eds.). Ecological communities: conceptual issues and the evidence. Princeton Univ. Press, Princeton, N. J.

Wiper, M.P., and S. French. 1995. Combining experts' opinions using a normal- Wishart model. J. Forecasting 14:25-34. 